\title{
Labor as One of the Core Values of a Competitive Expert in Agricultural and Engineering Industry
}

\author{
Svetlana V. Kulikova \\ Northern Trans-Ural State Agricultural University \\ Department of Mathematics and Computer Science \\ Tyumen, Russia \\ s.culickova2010@yandex.ru
}

\author{
Nadezhda N. Malchukova \\ Northern Trans-Ural State Agricultural University \\ Department of Mathematics and Computer Science \\ Tyumen, Russia \\ Npescova06@yandex.ru
}

\author{
Tatyana A. Konova \\ Tyumen Military Engineering Command High School \\ Department of Natural-Sciences and General Professional Disciplines \\ Tyumen, Russia \\ tatkoten@mail.ru
}

\begin{abstract}
The education at any higher educational institution shall focus on students' ability to predict and correct their future activity within general cultural competences. The paperconsiders labor as one of universal human values aimed to improve the intelligence level of future engineers thus accelerating the development of a competitive expert and promoting intellectual resources of agro-industrial enterprises.
\end{abstract}

Keywords-value, labor, diligence, professional activity, competitive expert, intellectual resource.

\section{INTRODUCTION}

The main task of any higher educational institution is to increase competitiveness of its graduates in the labor market, which requires the development of general cultural, general professional and professional competences stipulated in corresponding Federal State Educational Standards of Higher Education (FSES HE), i.e. to help its graduates to become competent in solving various tasks related to their future profession

The term 'competitiveness of university graduates' is quite complicated. Oganyan K.M. notes that the "competitiveness of a graduate is defined by the quality of his/her training at a higher educational institution, namely practice-oriented training and development of personal readiness for future professional activity" [1]

A.A. Malysheva and I.V. Nevrayeva believe that a university graduate becomes competitive by acquiring "either expertise forming high demand in the market, which cannot be replaced with personal qualities, or special personal qualities required by the market economy besides knowledge gained at a higher educational institution" [2].

Intellectual resources of an enterprise, including agricultural ones, are composed of "a set of intellectual forms of individuals (physical resource, mental resource, social resource, emotional resource, spiritual resource)" [3].

The development of a society is defined by its intellectual resources and universal human values. The intellectual base of a future competitive engineer depends on the level of development of his/her personal qualities, one of which is the diligence. The diligence is formed through such universal value as labor.

The need to develop the universal human values in Russia is reflected in the National Doctrine of Education in the Russian Federation and the Concept of Spiritual and Moral Development and Education of the Russian Identity.

The main objective of the higher school stated in the Concept of Modernization of Russian Education Until 2025 is to train not only a highly-qualified and responsible expert able to withstand the competition in labor market, but also a highly-moral, spiritually developed personality responsible for the destiny of the country and its social and economic prosperity.

The agro-industrial complex needs agricultural workers that are not afraid of difficulties and are ready for innovations. This is caused by the fact that individual improvement is achieved through labor to increase the intellectual level and to become a qualified specialist.

Let us consider general cultural competences. The FSES HE approved in 2015 for the training program 35.03.06 Agricultural Engineering (bachelor degree) states that the university shall foster the development of one of the following competences: ability to communicate in oral and written forms in Russian and foreign languages to solve interpersonal and inter-cultural tasks (5); ability to work in a team demonstrating tolerance towards social, ethnic, religious and cultural differences (6); ability to self-organization and self-education (7).

The analysis of general cultural competences makes it possible to conclude that they are based on universal and personal values of an individual, one of which being labor. Labor, in turn, forms the basis for future work of university graduates. As a rule, according to the curriculum the general cultural competences within engineering programs are formed through humanities. It is impossible to solve this task concentrating on certain disciplines only. The development of 
competences and competence in general shall run like a scarlet thread through the entire training period, including in-class and out-of-class learning.

Sustainable development of a positive attitude to labor requires measures motivating students to diligence. Tutors of university student groups may contribute to the solution of this problem. The tutor may foster the development of individual competence - readiness for continuous professional development and self-fulfillment, ability to self-motivation, reflection, self-development in professional life.

Labor, being the driver of human development and progress for the younger generation, took a back seat against material security in the hierarchy of values. According to the survey conducted by the Russian Public Opinion Research Center (VCIOM) in 2018 and published by Russia Today, the following are considered typical characteristics of the younger generation: sociability, accuracy, love for sports and committment to material values. It shall be noted that labor was not included in this list. According to VCIOM, young citizens aged from 16 to 24 consider themselves cynic (56\%), people aged 25-34 years characterize themselves as quite rebellious $(52 \%)$. On the contrary, the senior generation perceives the modern youth as more friendly and altruistic.

With regard to professional development it is critical to consider the ideas of L.P. Buyeva, V.Ya. Suslov, M.V. Dyomin on the relation between 'labor' and 'work', 'activity'; E.A. Klimov, J. Rolz, A. Maslow, E. Fromm, F. Herzberg - on interpretation of labor through such categories as 'sense of worth (identity)', 'dignity', 'labor prejudices', 'team work', 'labor motivation', etc.; D.L. Gegeshidze - on division of labor into intellectual and physical; G. Hegel, I. Kant - on self-fulfillment through labor; F. Engels, K. Marx - on labor as a condition of existence of the mankind; A. Arvon, L. Mumford, E. Mounier - on value and 'non-value' of physical and intellectual work. Labor affects the development of positive qualities and makes a person a master and a professional expert [4].

Let us consider the attitude to labor being a universal human value of future engineers as one of the educational objectives at any university. Labor plays a key role in life of each person [5].

Modern science includes several definitions of 'value'. P. Mentzer defines the value as something a person shall strive towards, treat with recognition, respect, dignity since it is the ultimate value. S.V. Kulnevich links values with preference or rejection of certain meanings helping a person to choose the modes of behavior [6].

A great philosopher Giordano Bruno calls labor as the basis for individual moral values. "I am against - says the philosopher, - any idleness, negligence, laziness" [7].

The educational process at a higher educational institution shall pay attention to students' ability to predict the future professional activity within the competence-based approach enjoying such universal value as labor, to understand at what level this ability is developed. A future engineer shall develop this ability in a way that he/she is able to correct the labor activity independently, understand that only labor will help to achieve good results and to increase the intellectual level to become a competent expert.

\section{MATERIALS AND METHODS}

The study was held at the Northern Trans-Ural State Agricultural University in 2016-2018 academic years and covered 125 students. The study was conducted during the out-of-class hours. The following were used as the methods of study: analysis of materials on psychology, pedagogy and methodology concerning a research topic, questionnaire survey and testing; comparative analysis of findings; qualitative and quantitative analysis of obtained data.

\section{ANALYSIS OF THE STUDY}

The study was conducted in two stages. The first stage covered the first-year students of 2016-2017 academic year during tutor hours, the purpose of which was to motivate the first-year students in agricultural engineering of the Northern Trans-Ural State Agricultural University for sustainable positive attitude to universal values, including labor. The second stage was carried out with the same students' cohort that joined the second year of study. The purpose of the second stage was to reveal changes of students' attitude to the studied subject.

The first stage included the opinion poll and the questionnaire survey of the first-year students, thematic tutor hours aimed to develop personal qualities of a competitive expert through the positive attitude to universal values. Students think that it is the task of tutors to focus on labor education at the university. Throughout the study at the university students shall feel support from their tutor that fosters a friendly environment within a group [8].

The initial stage of the study included the survey of students concerning their knowledge and understanding of universal values. When asked what values are considered universal, the student gave answers reflected in Fig. 1.

The traditional attitude towards family has always been passed on from generation to generation and is still considered one of the main values in the Russian society. It was positive that the attitude of modern students to family is serious similar to people of the senior generation, despite the attempts in recent decades to disrupt the attitude towards traditional values. The respondents placed the family first (53\%) among other values, since family and marriage relations hold a prominent place throughout the formation and development of young people [9]. It was not surprising that kindness (13\%) and love $(10 \%)$ turned to be less valuable but also important. For the Russian society, kindness and love along with family are traditionally interrelated and are based on spirituality, which was confirmed by $8 \%$ of respondents. Another $7 \%$ of respondents value friendship and humanism after cheerfulness and mercy (4\%). Loyalty, commitment, sincerity, goodness, disinterestedness were mentioned less often (1\%) though these concepts belong to personal qualities but not values. It was rather strange to find scepticism and leisure (other) in this list since they were never considered the universal values. 


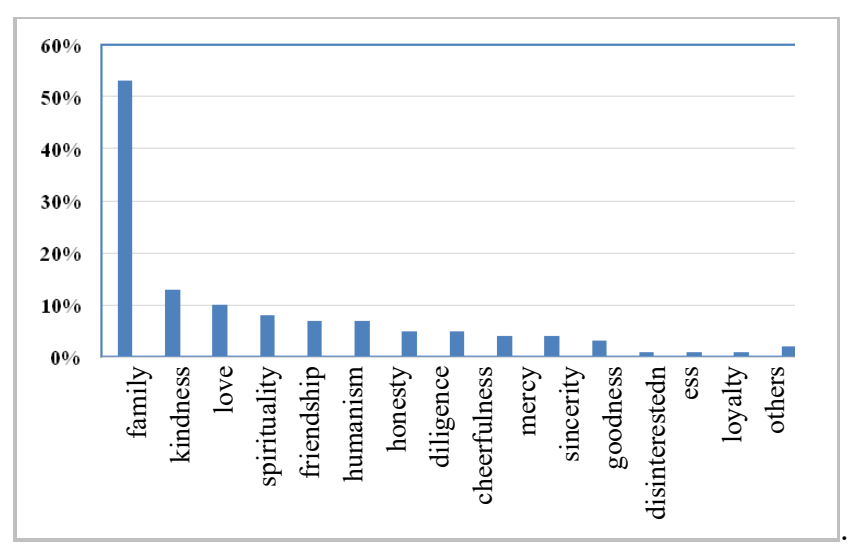

Fig. 1. General universal values

The attitude of future engineers to diligence raised some concerns. Only $5 \%$ of respondents thought of this personal quality believing that it is a universal value. Despite single opinions of respondents such as "no pains, no gains", "no cross, no crown", "work helps to pursue goals" and "progress is achieved through work", the general perception of diligence remains uncertain. Many of them failed to think of benefits of work and diligence in human life in general and life in particular and hence do not perceive labor as the basis for future professional activity.

The first-year students were offered to evaluate the level of importance of such universal values as person, traditions, communication, knowledge, beauty, homeland, work and life. The results are shown in Fig. 2.

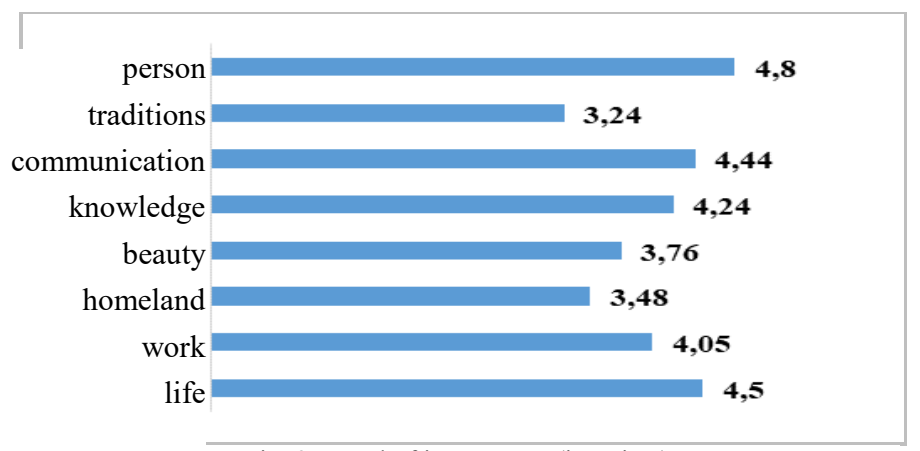

Fig. 2. Level of importance (in points)

Figure 2 shows that person and life are considered the most important values, which indicates a relatively high level of egoism among the first-year students. Besides, communication is also an important value for students. Most likely it is important for students to exchange their thoughts and feelings in order to increase self-esteem or simply to have a good time with their friends. Knowledge and work were marked as average. Knowledge includes the improvement of cultural standards, personal enrichment and development of intellectual abilities of a person. One of the forms of knowledge is the study at the university. Since this value was not the most important, it is possible to assume that the study is not the priority for young people. It was interesting to know the attitude of respondents to work. The fact that work takes an average position among all values means that a person understands its importance but, at the same time, it is not the priority. This means that students perceive work only as a necessary condition of life and a responsibility of every person. The experts were surprised by low level of importance regarding beauty. Perhaps this happened since the majority of respondents were male. Such result slightly contradicts the opinion of experts that believe that "beauty, in particular the body beauty, will become one of the key universal values" since recent social, economic and cultural transformations in Russia led to new trends in the attitude of young people to their health [10]. The sad fact is that homeland and traditions, being very important for Russia, took the last places in the hierarchy of values. Most likely these values are pushed out by egoism. This indicates insufficient patriotic education at school and at home.

The tutor schedule was made to implement the first phase of the study. It is known that the love of labor may be taught through personal work only, and at the university it is possible to join such activity by participating in students teams. Therefore one of the first tutor hours for the first-year students studying Agricultural Engineering was devoted to a meeting with officers and fighters of students' teams of the Northern Trans-Ural State Agricultural University. The objective of the tutor hour was to motivate students for work in students' teams during summer break.

The tutor hour was held as a press conference. Each representative briefly introduced the team and shared the specifics of work. It was mentioned that the university fosters the creation of specialized students' teams according to professional profile. The fighters of the Energiya team lay electricity wiring in new buildings of the city. The Brigantina team is created for future agricultural engineers. It is engaged in landscape gardening of the university campus and other objects in the city. The Mekhanizator team helps various agricultural enterprises of the south of Tyumen region with sowing and harvesting. The fighters of the Mechta pedagogical team work as leaders in children's camps. The Vodnik team is created for future ichthyologists. The firefighting team was established at the university in 2012 for students studying Fire Safety. The member of the regional head office presented the activities of regional students' teams.

At a briefing, the first-year students had an opportunity to ask several questions. Students were interested in everything: why the representatives preferred work in students' teams instead of summer vacation, what is the salary, what is the working schedule, in what facilities and organizations do the fighters work, what are the required documents to become a fighter of a students' team? The representatives answered all questions honestly and with enthusiasm, explained what personal benefits they get from such work, what lessons they learned from work in a team and what personal qualities they were able to develop. The representatives explained that no one creates hothouse, comfortable, convenient conditions for work to fighters of students' teams. Students learn to live and work in the conditions close to reality, which they will face upon graduating from the university [11]. 
The first-year students listened with genuine interest. They wanted to learn as much as possible about work in such teams and to decide whether to join such labor movements. After the press conference, more than a third of the first-year students signed up for students' teams. It was interesting to observe the conversation, especially when students were asking about salaries. The work of fighters in various teams is paid differently. The fighters of the construction team have the biggest salary, while the pedagogical team has the smallest. In fact, the students were facing an internal dilemma - what to prefer: a good salary or professional experience? Everyone solved this matter according to personal preferences. For example, the majority of students studying Electric Equipment and Technologies chose occupational guidance and signed up for the Energiya team where they will learn to lay internal wiring in buildings under construction. The students of Technical Systems and Technical Service preferred the Mekhanizator team where they can work on modern agricultural machinery. Two students, feeling some pedagogical potential, signed up for the Mechta team. Other students picked the regional construction team.

The next stage implied that students pass training in work specifics of a chosen team within a year.

Our task is to ensure psychological training of the firstyear students for work in labor teams thus making them aware of the importance of universal values (work, friendship, goodness) and developing personal qualities (ability to compromise, kindness, honesty, disinterestedness, cheerfulness). The educational function of labor implies the development and strengthening of socially valuable qualities and properties among students during the labor process [12].

The next tutor hour was devoted to the solution of potential conflict situations in a labor team. The dynamics of social development constantly places higher demands on people [13]. The objective of the tutor hour is to tell students about all types of labor conflicts and ways of their solution.

Each person faces conflict situations in life, especially if you work in a labor team. A competitive expert shall be aware of different methods to eliminate such conflicts thus maintaining the same level of working capacity. Being a future company leader, he/she shall fix 'weak points' and manage staff in a competent and professional manner [14]. What are the negative and positive aspects of a conflict?

Let us describe the scenario of the tutor hour. The tutor hour is held in the form of a dialogue between a teacher and students.

Teacher. I would like to begin our tutor hour with the words by Abraham Lincoln (one of U.S. Presidents): a conflict is understanding, imagination or fear of at least one party that its interests are violated, restrained and ignored by another. It is when two or several parties are ready to fight for seizure, suppression or destruction of interests of their rivals to satisfy personal interests. In fact, a conflict is the competition to satisfy the interests, or a conflict of interests. Let us consider the conflict from a positive side.

Student. A conflict determines the true situation, reveals the opinion of conflicting parties, opponents share subjective views on a conflict situation. There is an outburst of new ideas, which contributes to the development of a team and self-improvement of its members.

\section{Teacher. What are the negative aspects of a conflict?}

Student. Conflicts cause stress, which negatively affects health and reduces positive attitude to work. It also makes a person not willing to be part of such team, which leads to internal breakup of a team. A person cannot think about work but is focused on the conflict. This causes irritability thus resulting in communication problems with other people. Bad mood can influence the emotional situation within a family.

Teacher. Having listened to both parties, we understand that all opinions are right. Nevertheless, it is better to settle a conflict or solve it without serious consequences.

Question. What labor conflicts can happen at any enterprise?

Student. (answers are prepared in advance). Interpersonal, horizontal, vertical, intergroup conflicts.

Teacher. How can we prevent these conflicts? What intellectual resource are available? First, we shall control anger, understand that we deal with one of the team members and hence shall treat him with respect. Second, we need to understand the point of view of a partner and try to find the best solution satisfying both parties. Third, we shall implement this solution and consider the outcomes.

Student. The most important thing in any situation is to be calm and soberly evaluate a situation.

Teacher. Of course. But what does it mean to stay calm? To treat others with respect, to keep your temper in check! Do not let the anger or fear of violence to conquer you. You need to speak quietly, avoid be personal and offensive, listen to the opinion of the opponent, and understand that it is always possible to reach a compromise. Try to shift from negative to humor.

Now it is time for a role-play to illustrate a conflict situation. Please, split into four groups. The first group thinks of a conflict between a manager and a team, the second between a leader and a subordinate, the third - between two colleagues regarding promotion, the fourth - between an employee and the entire team where he works. Then, each group role-plays a situation. You have 15 minutes to prepare for the role-play. After that, the students role-play conflict situations and give their evaluation.

Teacher. Let us summarize the result of our tutor hour. It is possible to solve a conflict if you are able to control your behavior, avoid focusing on your advantages, demonstrating superiority over others, and try to settle problems through convenient and fair solutions.

I would like to conclude with the words of a famous poet Natalia Evstigneeva:

Let us be careful with each other:

Avoid harsh words

Or 'petit point' needling

And cut out invoicing for good behavior. 
Let us do without slights and snubs

Psychological training will make students positive, will help to adapt quickly in a labor team and to avoid various mistakes in relations.

We were interested in the following question: how did the attitude of students to labor change after the tutor hours and after the engagement of the first-year students in students' teams. We carried out a comparative analysis of survey results. The questionnaire was twice given to the same students' cohort - at the first and at the second year of study. The results were as follows.

Five possible answers were suggested to define labor. The results are shown in Fig. 3.

At the first year of study the majority of respondents considered labor a vital necessity $(58 \%)$, which well coincides with the results of the opinion poll concerning the importance of values for a person. For the first-year students labor is a need, a certain responsibility, without which it is impossible to live, but which has no priority value.

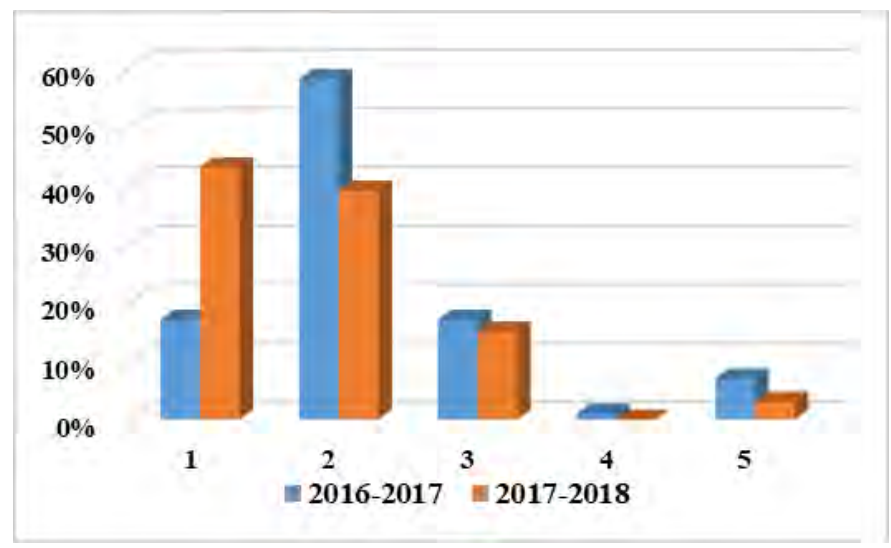

Fig. 3. Definition of labor:

1. purpose of human life; 2 . vital necessity; 3 . moral value; 4 . duty; 5 . other

$17 \%$ of respondents thought that labor is the purpose of human life and moral value. They treated this concept more philosophically than pragmatically. $1 \%$ of respondents (one person) defines labor as duty. Most likely, this person perceives leisure as a universal human value and labor for him is a complex task. $7 \%$ of respondents suggested their own definition, for example, labor is development, survival objective (coincides with the second possible answer in sense).

However, students changed their opinion at the second year of study. The percentage of those who consider labor as the meaning of life has sharply increased. Having gained some practical experience and mastering labor relations in students' teams, young people started to appreciate this value in their life and changed their attitude to positive. However, despite the fact that the number of those who consider work as vital necessity decreased, their percentage still remains quite high $(39 \%)$. Students need to be aware of the positive aspects of labor, they need to understand that work can bring joy. The number of students associating labor with moral values has slightly decreased. There were more pragmatists among the second-year students. Only $2 \%$ had another opinion different from the suggested options.

The students were also asked to give the unambiguous answer on whether it is possible to consider labor as the value of modern society. The majority of students replied in the affirmative (which was good), and their percentage increased at the second year of study from $70 \%$ to $84 \%$. Such high evaluation of labor by future engineers is not fortuitous since intellectual and physical labor will help them to fulfill themselves in a profession and to become competitive. Only a small amount of respondents answered in the negative $(16 \%$ and $11 \%$ respectively) believing that 'people became lazier' and need more rest. 14\% of the first-year students were not able to give their definition to labor since they never thought about it. At the second year of study this indicator decreased to $5 \%$. Perhaps, these students were not part of any students' team.

The analysis of the results makes it possible to conclude that the focused effort of tutors helped the majority of students to understand the importance of work for self-fulfillment in their future profession. The results are shown in Fig. 4.

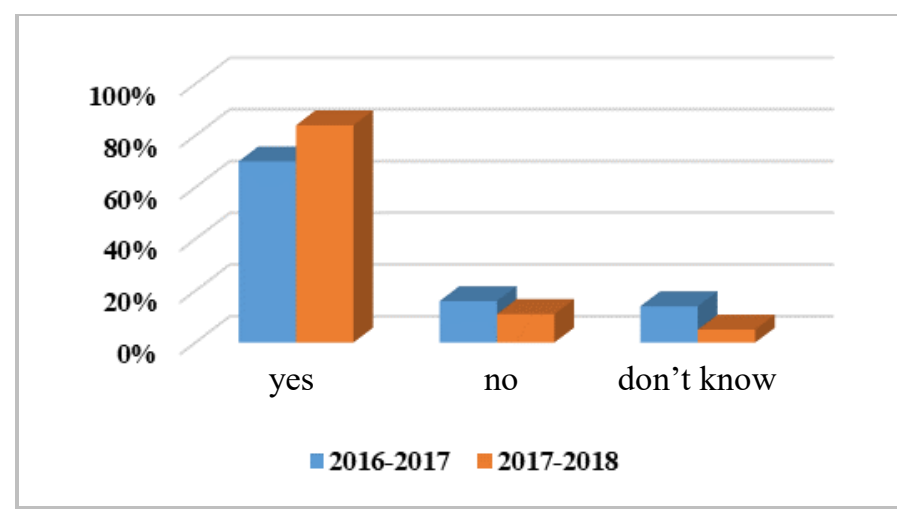

Fig. 4. Attitude of students to labor as to the value of modern society

It is important what personal qualities the young people consider key for their future performance in professional activity (Fig. 5).

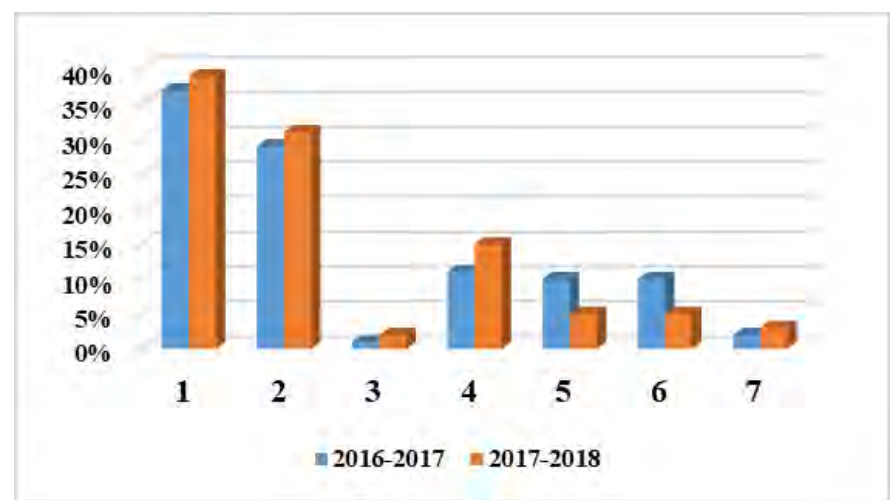

Fig. 5. Personal qualities helping to fulfill future professional potential: 1. professional knowledge; 2 . diligence; 3 . punctuality; 4 . mobility; 5 . will power; 6 . initiative; 7 . ability to follow the leader 
Both first- and second-year students identified two main qualities: professional knowledge (37\% and 39\% respectively) and diligence $(29 \%$ and $31 \%$ respectively). The students confirmed the importance of work and diligence for a person. However, mobility was less important, and the second-year students specified this quality more often $-11 \%$ during the first survey and $15 \%$ during the second. The reality of modern life forces people to react quicker to changes and updates of the information space. The first-year students paid attention to such qualities as will power and initiative (10\%), and at the second year of study these indicators decreased twice $(5 \%)$. Several first-year students considered the ability to follow the leader $(2 \%)$ as the main quality, while at the second year of study this opinion became stronger (3\%). Almost nobody marked punctuality (only $1 \%$ and $2 \%$ respectively). This means that tutors and teachers shall focus more on selforganization and self-discipline, "aimed at the acquisition of personal and professional experience" [15].

\section{CONCLUSIONS}

1. The importance of labor as the universal value is key in the development of personal and professional qualities of future agricultural engineers. The study revealed that diligence helps students to achieve success in their profession.

2. There is a need to ensure targeted educational process at a higher educational institution so that future agricultural engineers perceive diligence as the priority aimed to achieve career growth and self-fulfillment in a profession through the introduction of thematic tutor hours and promotion of students' labor teams.

3. Upon graduation from the university, a competitive specialist in agricultural engineering shall be diligent to be able to increase his/her intellectual potential throughout the career thus positively influencing the intellectual resources of enterprises within the agricultural sector of economy.

\section{REFERENCES}

[1] K.M. Oganyan, Sociological support of competitiveness among university graduates in the conditions of modern labor market: Joint monograph, Moscow: INFRA-M, 2015, p. 47.

[2] A.A. Malysheva, "Competences of young university graduates as viewed by employers", Notes of Tomsk Polytechnic University, 2010, vol. 8, p. 226.
[3] E.E. Golovchanskaya, "Intellectual resource as the main component to assess the intellectual activity of the national economy under modern institutional conditions in the Republic of Belarus", Problems of modern economy. Proceedings of the XXXVIII International Scientific and Practical Conference, 2017, pp. 59-63.

[4] Yu.P. Loginov, A.A. Kazak, "Labor education and professional orientation as the basis for training a modern agronomist for a village", Problems of value formation in education of rural youth: Proceedings of the International Scientific and Practical Conference, Tyumen: Northern Trans-Ural State Agricultural University, 2014, pp. 221-222.

[5] L.I. Yakobyuk, "The current stage of labor education in Russia”, Agrofood policy of Russia,. 2017, vol. 10 (70), pp. 162-165.

[6] T.N. Logacheva, Development of values-based attitude among high school students to cultural traditions in humanities: Cand. Sci. Dissertation: 13.00.01 Volgograd, 2004, p. 175.

[7] S.P. Akutina, Formation of moral values among high school students as one of the responsibilities of a homeroom teacher in the conditions of comprehensive teaching and educational process: Cand. Sci. Dissertation: 13.00.01 Nizhny Novgorod, 2003, p. 209.

[8] N.N. Malchukova, "Education as a primary activity of a tutor", Herald of the Northern Trans-Ural State Agricultural University, 2014, vol. 1 (24), pp. 92-93.

[9] O.N. Goncharenko, "Factors influencing the values of rural youth". Problems of value formation in education of rural youth. Proc. of the International Scientific and Practical Conference. 2014, pp. 197-201.

[10] L.I. Iakobiuk, M.V. Vinogradova, N.N. Malchukova, Y.V. Kryucheva, "Students of agrarian university: social profile in mirror of deviations", Espacios, vol. 38 ( 40), 2017, p. 17.

[11] S.V. Kulikova, "Role of students teams in acquiring professional experience. Integration of science and practice for the development of agro-industrial complex", Proc. of the All-Russian Scientific Conference. 2017, pp. 477-481.

[12] B.T. Likhachev, Pedagogics. Series of lectures: study guide, Moscow: Urait, 1999, p. 523

[13] E.A. Berezuyev, "Marginalization in Russia and marginalization of rural population", Modern scientific and practical solutions in agro-industrial complex. Proc. of the All-Russian Scientific and Practical Conference. 2017, pp. 238-246.

[14] N.G. Khairullina, O.V. Ustinova, G.V. Kuchterina, L.G. Agapitova, L.B. Medvedeva, "Set of values in the structure of labor behavior of personnel", Man in India, 2016, vol. 96, No.10, pp. 3957-3968.

[15] N.V. Biryukova, "The modernization project of the mathematics teaching process providing the formation of a personal sense of knowledge for students of non-core areas", Espacios. vol.39 (20), 2018, p. 4 